\title{
Formation and movement of ice accumulation waves under ice cover - an experimental study
}

\author{
Jun Wang ${ }^{1}$, Yifan $\mathrm{Wu}^{1}$, Jueyi Sui ${ }^{2 *}$, Bryan Karney ${ }^{3}$ \\ ${ }^{1}$ College of Civil Engineering, Hefei University of Technology, Hefei, China. \\ ${ }^{2}$ Environmental Engineering Program, University of Northern British Columbia, Prince George, Canada. \\ ${ }^{3}$ Department of Civil Engineering, University of Toronto, Toronto, Canada. \\ * Corresponding author. E-mail: jueyi.sui@unbc.ca
}

\begin{abstract}
Ice jams in rivers often arise from the movement of frazil ice as cover-load under ice cover, a process which is conceptually similar to the movement of sediment as bed-load along a river bed. The formation and movement of an iceaccumulation wave is one facet of a larger class of cover-load movements. The movement of an ice-accumulation wave obviously plays a crucial role in the overall process of ice accumulation. In the present study, experiments under different flow and ice conditions help reveal the mechanics of formation and evolution of ice-accumulation waves. In particular, suitable criteria for formation of an ice-accumulation wave are investigated along with the resulting speed of wave propagation. The transport capacity of frazil ice under waved accumulation is modeled by comparing those of experiments collected in laboratories, and the resulting equation is shown to be in good agreement with measured experimental results.
\end{abstract}

Keywords: Cover-load; Experimental results; Frazil ice; Ice-accumulation wave; Ice jam; Ice transport capacity; Moving speed.

\section{INTRODUCTION}

Both ice covers and ice jams occur frequently in northern rivers in the winter. The formation of an ice cover can cause serious water level fluctuations due to channel blockage and the increase in resistance associated with flow under the ice cover. If there is sufficient supply of ice, its accumulation under an ice cover can initiate formation of an ice jam with an associated increase in water level. As a consequence, ice-induced flooding may occur and hydraulic structures, such as pump stations and bridge piers/abutments, may be damaged or destroyed (Beltaos, 2012; Sui et al., 2002).

During the formation of a frazil ice jam, the rate of arrival of the incoming frazil ice clearly plays a fundamental role in determining both the thickness of the ice jam and the associated likelihood of flooding (Sui et al., 2005). Thus, for ice jams in natural rivers, estimation of the ice transport capacity is a crucial step in the assessment of risk (Gao et al., 2003). Overall, ice transport capacity plays a key role in determining the variation in water level under ice jammed condition (Sui et al., 2005; Wang et al., 2007a).

Many researchers have explored the mechanics of ice jam evolution using field measurements, laboratory experiments or both (Beltaos and Burrell, 2010; Sui et al., 2008). For example, using long-term field measurements, Beltaos studied ice jam thicknesses and water level variations during river breakup on the Matapedia River in Canada (Beltaos and Burrell, 2010). To measure flow and floating ice velocities, as well as ice cover thicknesses, Morse et al. used ADCP and IPS to assess field conditions in the St Lawrence River (Morse et al., 2011). Additionally, they recorded wind speed and air temperature, variables which also affect the ice process. Based on field measurements in the Hequ Reach of the Yellow River, Sui et al. investigated the evolution of frazil ice jams and the associated variation in water level (Sui et al., 1994, 2005). They not only described the variation of ice jam thickness, but developed a formula for estimating both ice jam thickness and water level.
To better understand ice accumulation, Wang et al. experimented with S-shaped and U-shaped flumes (Wang et al., 2007b, 2011) and were able to determine the critical Froude number for the initiation of jammed conditions in curved channels.

Numerical simulations of ice accumulation and the associated variation in water level have been undertaken by some researchers. Beltaos used RIVJAM model to simulate changes in water level caused by ice jams in a wide channel (Beltaos, 1993). Zufelt and Ettema simulated the variation in water level during both the formation of an ice jam and it subsequent breakup (Zufelt and Ettema, 2000). Zufelt and Ettema used an one-dimensional ice-water coupling equation to describe the dynamics of an ice jam. By means of either a one-dimensional or a two-dimensional model, Shen (2010) and Wang et al. $(2011,2013)$ simulated the formation of an ice jam and both ice accumulation and transport under jammed conditions. All of the previous simulation work forms the foundation of the present study.

Various methodologies exist for estimating the ice discharge during ice flowing periods. Frazil jam and surface ice jam are totally difference phenomena with different transport mechanisms. Since there are rarely research work regarding undercover transport and accumulation of frazil ice, we still included some important research results regarding surface ice jam in this paper. For example, Beltaos (1995) proposed following formula for the surface ice discharge during ice flowing period in early winter:

$$
Q_{i}=N_{i} B_{i} V_{S} D_{i}(1-p)
$$

where $Q_{i}$ is the surface ice discharge; $N_{i}$ is the surface concentration of the ice in flowing water; $B_{i}$ is the width of the water surface; $V_{S}$ is the surface water velocity; $D_{i}$ is the thickness of flowing ice blocks; and $p$ is the porosity of the ice jam. In addition, Nuttal (1973), Calkins and Ashton (1976) and Ackerman and Shen (1983) have also studied the surface ice discharge. On the basis of research work of Ackerman and 
Shen (1983), Urroz-Aguirre (1988) also develop the following formula for estimating the surface ice discharge during the ice flowing period:

$$
\frac{Q_{i}}{Q}=2.4\left(\frac{1}{\theta}\right)^{0.682}\left(\frac{D i}{L}\right)^{1.181}\left(\frac{L}{B}\right)^{0.845}\left(\frac{g B^{5} S_{0}}{Q^{2}}\right)^{0.317 Q^{0.135}}
$$

where, $Q_{i}$ and $Q$ is the ice discharge and flow discharge, respectively; $\theta$ is the side slope of the channel bank; $L$ is the equivalent diameter of ice block; $B$ is the bottom width of the channel; $g$ is the gravitational acceleration; and $S_{0}$ is the longitudinal slope of the channel bed. Based on laboratory experiments, Wang (2002) proposed a formula to determine ice discharge. Shen and Wang (1995) obtained the transport capacity formula of frazil granules. By comparing ice transport under ice cover (cover bed load) to sediment transport on river bed (bed load), Wang et al. (1993) claimed that both formulas proposed by Bagnold (1956) and Luque and Beek (1976) could be used to calculate ice transport capacity during the period when the ice jam is quasi-equilibrium. By using a small-scale, curved flume of rectangular cross section, Urroz and Ettema (1994) carried out experiments to study the initiation mechanisms of ice jam and the factor affecting to the maximum conveyance of ice under the curved channel. Urroz and Ettema (1994) identified two principal ice-jam initiation mechanisms, namely, lodgement and gorging. They claimed that channel roughness was found to have a significant effect in helping the arching mechanism that produces lodging.

Yet due partly to the high risk of conducting field measurements, and partly due to the complexity of the physical processes, ice accumulation in rivers is perhaps one of least understood subjects in river hydraulics. The majority of past work has focused on the ice accumulation that first produces an ice jam and the resulting variations in water level. Relatively little work has considered the formation and evolution of the iceaccumulation wave, with the few existing studies being quite basic. Based on experiments carried out in laboratory, Ettema and Huang (1988) determined the equilibrium thicknesses and forms of ice rubble accumulations beneath barges moving through ice-covered channels. They pointed out that significant amounts of ice may accumulate beneath a barge moving at creeping speed through a navigation channel covered by a sheet of ice, and that accumulation thickness decreases with increasing barge speed. However, in present study, the forces acting on ice particles are studied in order to obtain relations for the development of the ice-accumulation wave and the influence of the transport capacity, then, using experimental results, attempts to better understand the mechanics of an iceaccumulation wave.

\section{ICE-ACCUMULATION WAVE \\ Experimental setup}

The experimental study has been conducted in the flume at Hefei University of Technology. As shown in Figure 1, the flu- me has a dimension of $34.38 \mathrm{~m}$ long, $0.6 \mathrm{~m}$ deep and $0.4 \mathrm{~m}$ wide. There are 22 observation cross sections along the flume with an equal distance of $1.2 \mathrm{~m}$. The ice-hoper for adding model ice into the flume was placed at cross section 4. The model frazil ice used in this experimental study is made by polypropylene with the mass density of $0.918 \mathrm{~g} / \mathrm{cm}^{3}$, which is nearly the same as the mass density of natural ice of $0.917 \mathrm{~g} / \mathrm{cm}^{3}$. The model frazil ice particles used in this experimental study are uniform. They have a shape of oblate spheroid with a diameter of $0.35 \mathrm{~cm}$, and maximum thickness of $0.20 \mathrm{~cm}$. Flow depths are $10 \mathrm{~cm}, 15 \mathrm{~cm}, 20 \mathrm{~cm}$, and $25 \mathrm{~cm}$, respectively. The average approaching flow velocity are: $0.16 \mathrm{~m} / \mathrm{s}, 0.17 \mathrm{~m} / \mathrm{s}, 0.18 \mathrm{~m} / \mathrm{s}$, $0.19 \mathrm{~m} / \mathrm{s}, 0.20 \mathrm{~m} / \mathrm{s}$, and $0.21 \mathrm{~m} / \mathrm{s}$, respectively. The incoming ice discharge varies from $0.01 \mathrm{Liter} / \mathrm{s}$ to $0.04 \mathrm{Liter} / \mathrm{s}$.

\section{Formation of ice-accumulation wave}

The incoming ice floes from upstream are entrained and submerged under an ice cover if the water velocity is sufficiently high. Frail jam starts to form when the velocity is low enough so that frazil will float to the underside of the cover. This process marks the initiation of a river ice jam. The transport of frazil ice under the ice cover will clearly be significantly affected by flow velocity and grain size of the frazil ice particles. Field measurements and experiments show that the mechanics of movement of frazil ice particles under an ice cover is conceptually similar to the movement of sediment along a riverbed. Similar to bed load and suspended load of sediment in water, there are also suspended ice particles and "bed load" (defined as "cover load") ice particles in the water. Under specific flow and incoming ice conditions, similar to a sand-wave on a river bed, the cover load may develop waves. Such an "ice-accumulation wave" is an important type of ice movement under an ice cover. Yet the movement of "iceaccumulation wave" under an ice cover tends to be even more complicated than a sand wave due to its larger grain size and the continuing inflow of ice from the upstream.

As shown in Figure 2, along the flow direction, "A", "B" and "C" represents the "wave starting point", "wave crest", and "wave trough" of an ice-accumulation wave, respectively. Observations show that movement can be separated into three stages.

a) First, after initial formation of an ice cover, due to the drag force and shear force resulted from flowing current, the incoming frazil ice particles start to accumulate under the ice cover if the flow velocity is sufficiently high. The flow structure around the ice-accumulation wave gradually evolves. As shown in Figure 2, the A-B section of ice-accumulation wave is the stoss side of the ice-accumulation wave, and B-C section is the lee side of the ice-accumulation wave. Streamlines along the stoss side have the similar shape to ice accumulation surface of A-B section. However, streamlines along the lee side have a vortex shape due to associated turbulent effects.

b) Due to the continuous incoming frazil ice from upstream, the thickness at the wave crest of ice-accumulation wave increases. The flow structure results in high pressure on

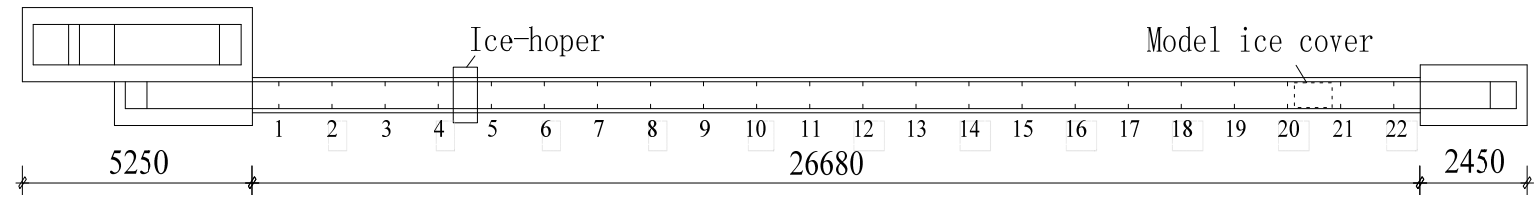

Fig. 1. The setup of experimental flume in the laboratory. 
(a)

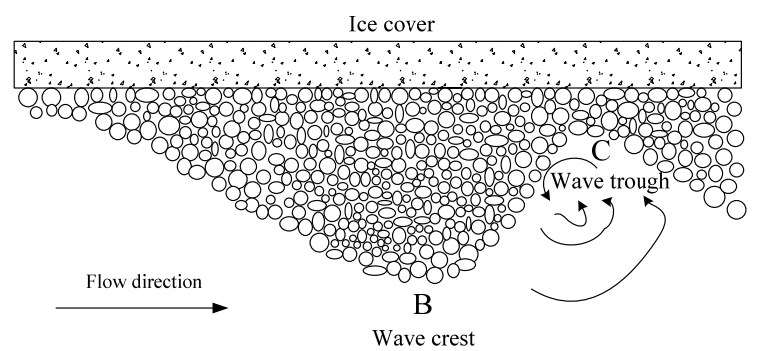

(b)

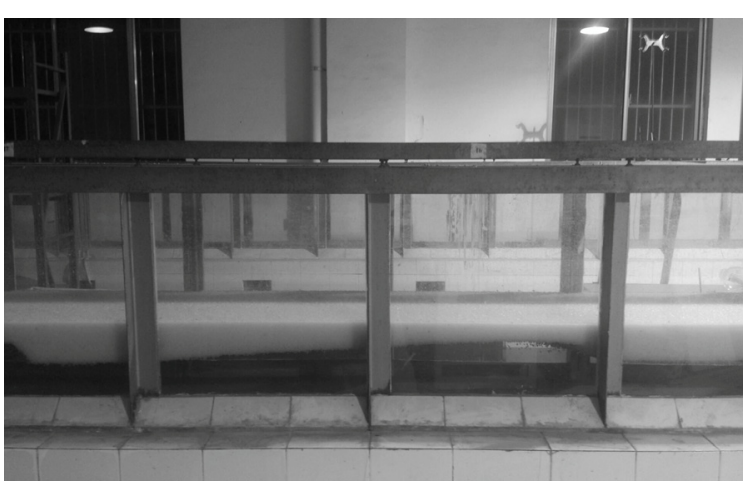

Fig. 2. The movement of "ice-accumulation wave". (a) Conceptual waved accumulation of frazil ice jam. (b) Waved accumulation of frazil ice jam in laboratory.

the stoss side of the ice-accumulation wave and low pressure on the steep lee side. This pressure difference produces the form drag force on the ice-accumulation wave. The drag force caused by the ice-accumulation wave and the continuous incoming frazil ice cause the ice-accumulation wave to propagate downstream. The wave height of ice-accumulation wave (vertical distance from wave trough to wave crest) gradually increases. Progressively more frazil ice particles on the stoss side A-B of ice-accumulation wave begin to move. The transport speed of frazil ice particles gradually increases. More and more frazil ice particles accumulate in the vicinity of wave crest. As a consequence, the stoss side A-B of ice-accumulation lengthens relative to the lee side.

c) With the gradual accumulation of ice, the flow intensity under ice jam increases with the turbulence intensity greatest at the wave crest. As a consequence, the transport speed of frazil ice particles there is the greatest. After passing the wave crest point (B), ice particles enter the lee side B-C. The lee side experiences vortex flow, and thus the flow intensity on the lee side decreases significantly. Thus, there is insufficient energy on the lee side to further transport the ice particles and ice accumulates there. Thus, both the wave crest and lee side move downstream and the ice-accumulation wave naturally propagate from upstream to downstream.

As does the movement of a sand wave on a riverbed, the formation and development of ice-accumulation wave is closely related to the flow intensity. Under open channel conditions, the interaction between flowing water and riverbed results in the formation of sand waves on the riverbed. The sand wave is but one type of riverbed surface forms. The instability of the viscous sublayer on the riverbed forms and develops the sand wave. Some researchers point out that the formation of sand waves also has a close relationship to the surface water waves (Shen and Wang, 1995). They developed a set of dimensionless variables to account for these effects.

There are also some important differences between the movement of "cover-load" and bed load. For bed load, the gravity force acting on sediment particle is larger than the buoyancy force since sand has a larger mass density than that of water. However, for the cover-load, though the buoyancy force generates a net upward force, its relative intensity is much less than that experienced by the sediment (that is, the sediment density different from water much more than the ice does). Additionally, the shear stress acting on these two different kinds of solid particles in water is also different. Thus, the incipient velocity for frazil ice particle to start to move should be less than that for sediment particle with the same grain size. Clearly, less energy is needed to transport ice particle downstream. Therefore, as observed in experiments, the wavelength of ice-accumulation wave is much greater than that typical of sand dunes in water. In our experiments, the measured wavelength of ice-accumulation waves ranges from $0.9 \mathrm{~m}$ to $1.2 \mathrm{~m}$. Additionally, the wave height of ice-accumulation wave changes with the flow intensity.

It should be noticed that the wave length is affected by many variables, such as ice particle size, flow intensity, energy slope, etc. However, in this experimental study, only one size of frazil ice particles is used. Further research work regarding wave length affected by other factors should be continued.

As observed in experiments, after moving some distance, the suspended frazil ice particles in water gradually accumulate under ice cover, and then are transported downstream as coverload. During the development of frazil ice jam, ice jam thickness also increases. The cross-sectional area for the flow under an ice jam decreases, and the flow velocity (and intensity) increases. Once the flow intensity reaches to a threshold level, the accumulated frazil ice particles start to form an iceaccumulation wave. With further increase in flow intensity, both the wavelength and wave height of ice-accumulation wave increase and the movement of the ice-accumulation wave becomes obvious.

However, similar again to the case of sand waves, the iceaccumulation wave cannot be maintained if the flow intensity is too great. Under a high enough flow intensity, the frazil ice particles will not accumulate but will be transported downstream as wash-load. The flow intensity is thus crucial for the development of an ice-accumulation wave as is the rate of incoming frazil. Experiments show that, if the incoming ice discharge is too low, an ice-accumulation wave is unlikely to form. However, if the incoming ice discharge suddenly increases, a single ice-accumulation wave will likely develop. During the development and disappearance of an ice-accumulation wave, flow intensity also changes. In the present study, the flow Froude number was used to describe the threshold flow intensity relevant for an ice-accumulation wave. Depending on the particle size, there exists the minimum flow intensity (or Froude number) for developing the ice-accumulation wave. The minimum flow Froude number is defined as the lower critical Froude number for the development of ice-accumulation wave. There is also the upper critical Froude number that allows for development of ice-accumulation wave.

Based on laboratory experiments, the relationship between water depth $(H / B$, where $H$ is water depth and $B$ is the channel width) and critical Froude number $(F r)$ for development of iceaccumulation wave has been plotted in Figure 3. Figure 3 makes quite evident the upper Froude number for developing ice-accumulation wave. However, the lower critical Froude number for developing ice-accumulation wave is not as clearly evident. This may be caused by the continuous variation in flow intensity during the development of ice-accumulation wave. Even if the initial flow intensity (or Froude number) is too low for an ice-accumulation wave to develop, with the continuous 
accumulation of frazil ice under ice cover, the flow intensity (Froude number) gradually increases. When flow intensity reaches the threshold value, the ice-accumulation wave will form. If the flow intensity is more than the upper critical Froude number, namely, the flowing water has so much energy that frazil ice particles are unable to accumulate under ice cover, they will be delivered downstream. One can also see from Figure 3, under the condition of the same discharge, when water depth $(H / B)$ is small, it is more difficult to develop iceaccumulation wave since the flow intensity is strong.

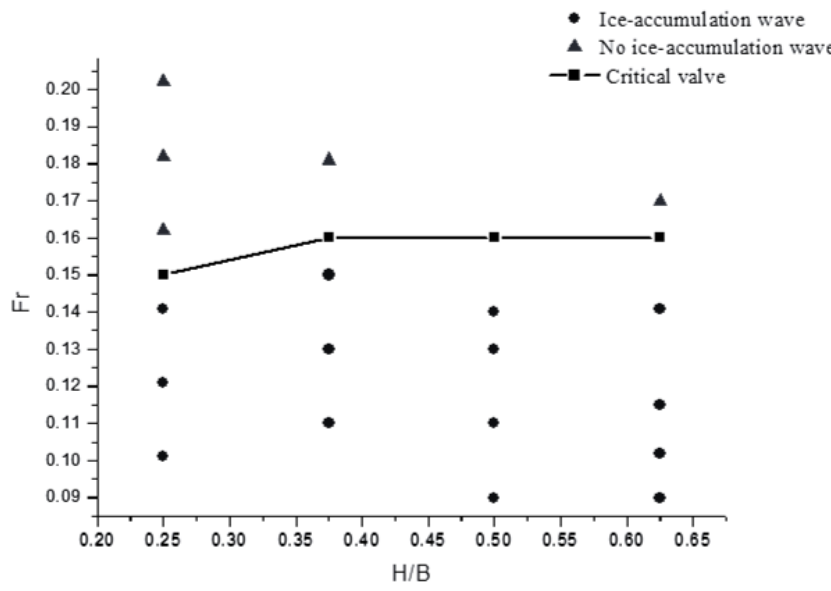

Fig. 3. Relationship between water depth $(H / B)$ and critical Froude number $(F r)$ for development of ice-accumulation wave.

Figure 4 shows the relationship between the wave height ( $H_{S} / B$, where $H_{S}$ is the wave height) and flow Froude number for the same water depth $(H=0.15 \mathrm{~m})$. One can see from Figure 4 , the more the flow Froude number, and the larger the wave height.

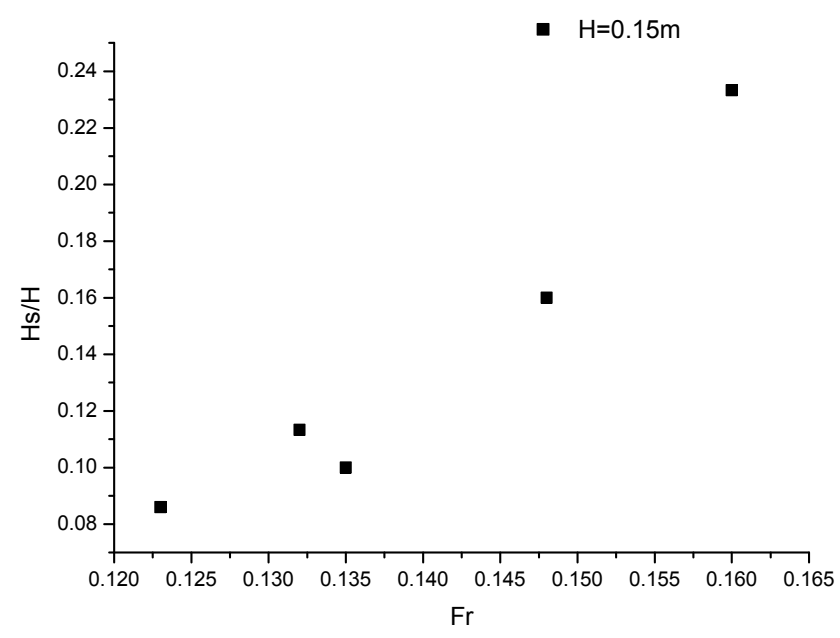

Fig. 4. Dependence of wave height $\left(H_{S} / B\right)$ on flow Froude number $(F r)$ for the same flow depth of $H=0.15 \mathrm{~m}$.

As for a sand wave, the development of an ice-accumulation wave likely results from an instability of viscous sublayer close to the ice cover boundary. At the beginning of the development of ice jam, the non-uniform distribution of ice jam thickness leads to the difference in flow velocity profiles at different locations, and therefore the formation of ice-accumulation wave. The development of ice-accumulation wave is not only controlled by flow intensity, but also affected by the imbal- anced shear forces acting on frazil ice particles, as well as the turbulence energy of flow. Due to rapid changes in the elevation of bottom surface of ice accumulation, the flow intensity also quickly changes. This relation tends to facilitate development of an ice-accumulation wave.

\section{Characteristics of ice-accumulation wave}

During the development of ice-accumulation wave, flow current acts on the bottom of ice-accumulation wave. Depending on the kinetic energy of flowing water, the moving speed of ice particle is different, and thus the changes in ice accumulation. On the other side, different moving speed and amount of the cover-load will also affect the structure of flowing current. As a consequence, the kinetic energy of flow current will change. This interaction between moving ice particles and flowing current exists during the entire movement of iceaccumulation wave.

In present study, we chose the first ice-accumulation wave from the upstream as the main focus, and pressure forces acting on flowing water body under ice-accumulation wave are given in Figure 5.

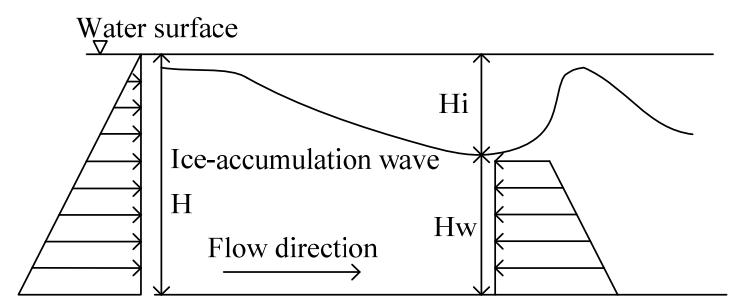

Fig. 5. Pressure forces acting on flowing water under iceaccumulation wave.

The continuity equation can be written as

$H V=H_{w} V_{W}$

where $H$ is water depth at the frontal edge of ice-accumulation wave (or total water depth); $V$ is the average flow velocity at the frontal edge of ice-accumulation wave; $H_{W}$ is water depth under the wave crest of ice-accumulation wave; $V_{W}$ is the average flow velocity under the wave crest of ice-accumulation wave. The momentum equation along the flow direction for control volume of water under ice-accumulation wave can be written as

$\sum F=\rho Q\left(V_{W}-V\right)$

where $\Sigma F$ is total force in flow direction; $\rho$ is mass density of water; $Q$ is the discharge.

The key forces acting on ice-accumulation wave include the difference of pressure force $\left(F_{P}\right)$ between the pressure force at upstream cross section (at the frontal edge of ice cover) and the pressure force at downstream cross section (at wave crest of ice-accumulation wave) and the form drag force $\left(F_{1}\right)$ acting on the ice-accumulation wave. The mass force along the flow direction can be ignored since the channel bed is horizontal and the water surface slope is tiny. These forces can be further described as following,

$F_{P}=\frac{1}{2} \rho g B H_{i}^{2}$ 


$$
F_{1}=\frac{1}{2} C_{0} H_{i} \rho B V^{2}
$$

Combining Equations (3), (4), (5), and (6), results in

$$
\rho H B V\left(\frac{H V}{H-H_{i}}-V\right)=\frac{1}{2} \rho g B H_{i}^{2}-\frac{1}{2} C_{0} H_{i} \rho B V^{2}
$$

where $C_{0}$ is the drag coefficient; $H_{i}$ is the wave height of iceaccumulation wave. Thus, we finally obtain the following relations:

$$
H_{i}=\frac{H}{2}+\frac{C_{0} V^{2}}{2 g}-\frac{\left[\left(g H+C_{0} V^{2}\right)^{2}-4 g H\left(2+C_{0}\right) V^{2}\right]^{\frac{1}{2}}}{2 g}
$$

$$
\begin{aligned}
& \frac{H_{i}}{H}= \\
& \frac{1}{2}\left\{1+C_{0}\left(\frac{V}{\sqrt{g H}}\right)^{2}-\left[\left(1+C_{0}\left(\frac{V}{\sqrt{g H}}\right)^{2}\right)^{2}-\left(8+4 C_{0}\right)\left(\frac{V}{\sqrt{g H}}\right)^{2}\right]^{\frac{1}{2}}\right\}
\end{aligned}
$$

From Equation (9), one can see that the wave height of iceaccumulation wave $\left(H_{i}\right)$ depends on the flow Froude number $(\mathrm{Fr})$ which is used to describe the flow intensity. The larger the flow Froude number $(\mathrm{Fr})$ is, the larger the wave height $\left(H_{i}\right)$. However, as the flow Froude number $(F r)$ increases to certain level, the wave height $\left(H_{i}\right)$ decreases. The form drag force coefficient of ice-accumulation wave $\left(C_{0}\right)$ depends on the incoming ice discharge $\left(Q_{i}\right)$, grain size of ice particle $\left(d_{i}\right)$ and roughness coefficient of bottom surface of ice-accumulation wave $(n)$. The form drag force coefficient of ice-accumulation wave $\left(C_{0}\right)$ can be expressed following,

$$
C_{0}=F\left(Q_{i}, d_{i}, n\right)
$$

Experiments indicate that the incoming ice discharge $\left(Q_{i}\right)$ is the most important factor affecting the form drag force coefficient of ice-accumulation wave $\left(C_{0}\right)$. This coefficient $\left(C_{0}\right)$ ranges from 5.5 to 12.5 , it increases with the increase in the discharge of the incoming ice $\left(Q_{i}\right)$.

The mechanics of ice-accumulation wave helps to better understand ice accumulation process under ice cover. The moving speed of ice-accumulation wave $\left(V_{i}\right)$ is obviously a key variable for describing the development process of ice-accumulation wave. The moving speed of ice-accumulation wave is the key factor controlling ice transport. Additionally, the moving speed of ice-accumulation wave will affect the turbulence intensity of the flow under the ice jam. As deduced from experiments, the transport speed of the ice-accumulation wave mainly depends on the flow Froude number, as shown in Figure 6.

As shown in Figure 6, with a flow depth of $H=0.15 \mathrm{~m}$, the moving speed of ice-accumulation wave has a strong relationship with flow Froude number. Thus, if the flow depth is the same, the propagation speed of ice-accumulation wave clearly increases with flow Froude number. One can also say that, after formation of ice-accumulation wave, the celerity of the iceaccumulation wave will increase with the flow intensity.

Figure 7 shows the relationship between moving speed of ice-accumulation wave and the water depth of $(H / B)$ for the

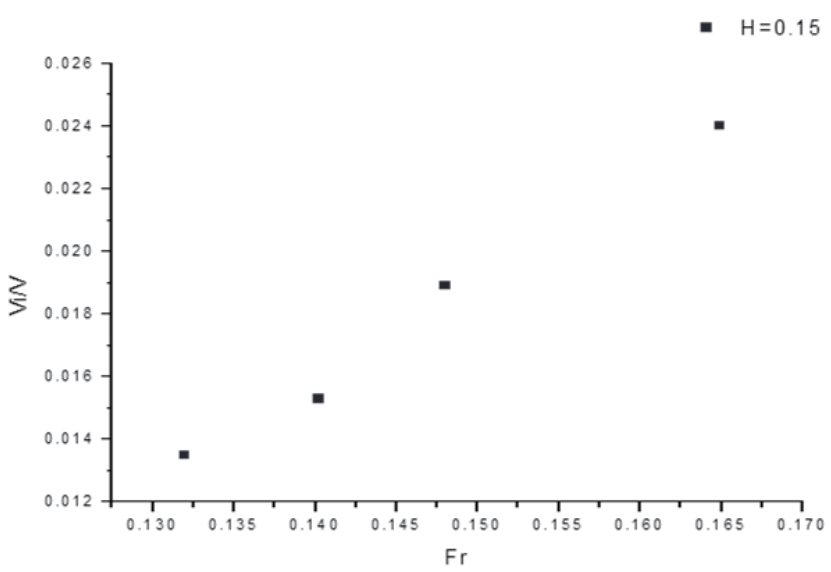

Fig. 6. Relationship between the moving speed of ice-accumulation wave $\left(V_{i} / V\right)$ and flow Froude number $(F r)$ for flow depth of $H=$ $0.15 \mathrm{~m}$.

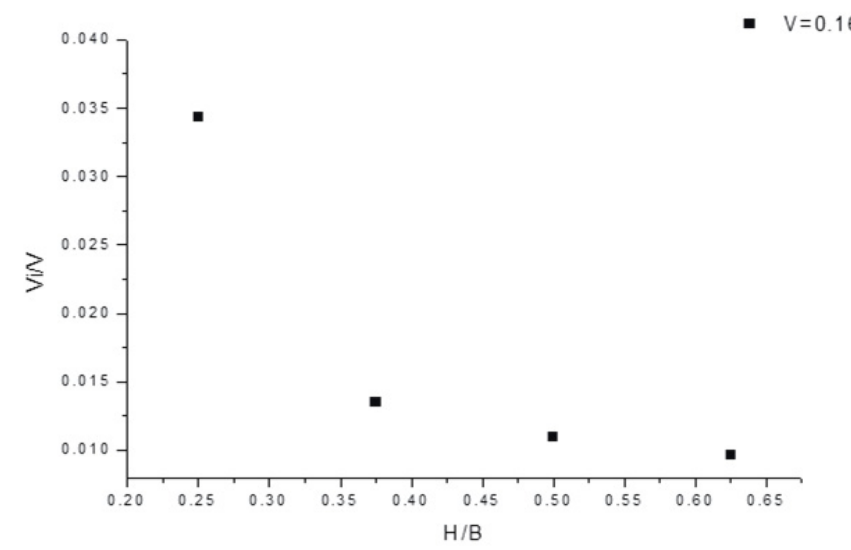

Fig. 7. Relationship between moving speed of ice-accumulation wave and water depth for the initial average flow velocity of $V=0.16 \mathrm{~m} / \mathrm{s}$.

initial average flow velocity of $V=0.16 \mathrm{~m} / \mathrm{s}$ under open flow condition. Figure 7 indicates that the moving speed of iceaccumulation wave decreases with the increase in the water depth. The increase in water depth results in the decrease in the transport capacity of ice particles under ice cover.

Considering all factors affecting the moving speed of iceaccumulation wave, the moving speed of ice-accumulation wave $\left(V_{i}\right)$ can be written as follows:

$V_{i}=F\left(V, H, g, n_{i}, n_{b}, \rho_{i}, \rho, B, d_{i}, h_{i}, Q, Q_{i}, L, T, J\right)$

where $V$ is the average flow velocity of flow under ice jam; $n_{b}$ and $n_{i}$ is the roughness of channel bed and ice jam, respectively; $\rho_{i}$ and $\rho$ is the mass density of ice and water, respectively; $h_{i}$ is the water depth under ice jam; $L$ is the length of the ice jam; $T$ is the air temperature during river freeze-up; and $J$ is the hydraulic slope. Neglecting dependent variables and less significant factors, Equation (11) can be further reduced to the following form:

$$
\frac{V_{i}}{V}=k_{1}\left(\frac{V}{\sqrt{g H}}\right)^{a}\left(\frac{H}{B}\right)^{b}\left(\frac{Q_{i}}{Q}\right)^{c}\left(\frac{d_{i}}{h_{i}}\right)^{m}
$$

where $k, a, b, c, d, m$ are coefficients 
Based on data collected from experiments in laboratory, the moving speed of ice-accumulation wave has strong relationships with the flow intensity $(F r)$, ice discharge $\left(Q_{i} / Q\right)$ and water depth $(H / B)$. Based on experiment data, the following regression formula has been derived for determining the propagation speed of ice-accumulation wave with regression coefficient of 0.94 as shown in Figure 8.

$\frac{V_{i}}{V}=0.5107\left(\frac{V}{\sqrt{g H}}\right)^{1.745}\left(\frac{H}{B}\right)^{-0.301}\left(\frac{Q_{i}}{Q}\right)^{0.026}$

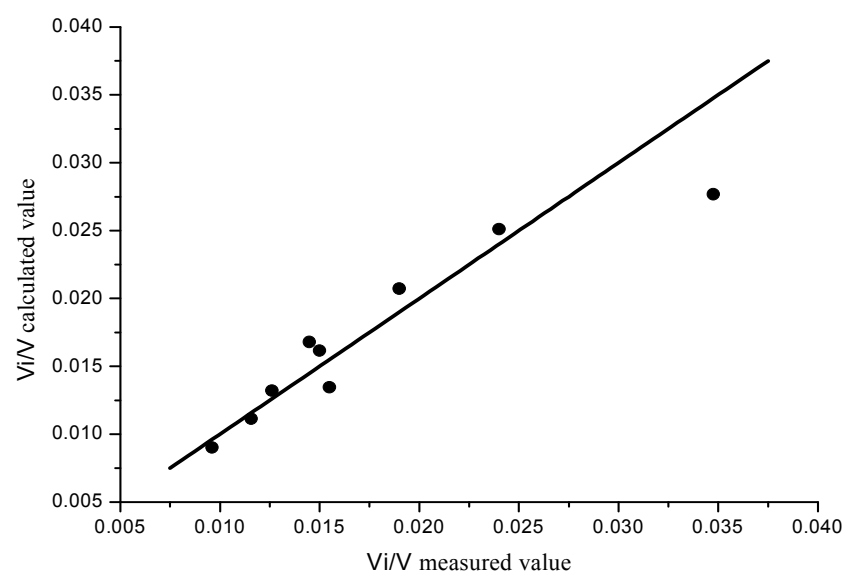

Fig. 8. Comparison of calculated moving speed of iceaccumulation wave to the measured moving speed of iceaccumulation wave.

One can see from Eq. (13), with the increase in flow intensity $(F r)$, the propagation speed of ice-accumulation wave increases; the propagation speed of ice-accumulation wave decreases with the increase in water depth, however, an increase in ice discharge $\left(Q_{i} / Q\right)$ results in an increase in the propagation speed of ice-accumulation wave. Unfortunately, we only have one uniform model ice particle $\left(d_{i}=0.35 \mathrm{~cm}\right)$, and the impact of grain size of ice particles on the moving speed of iceaccumulation wave cannot be considered. In our future studies, we will consider the effects of different grain size of ice particles on ice accumulation process.

\section{Transport capacity of cover-load}

The movement of the cover-load is the most important form of ice particle transport under an ice cover. Experiments show that the existence of the ice-accumulation wave affects the transport capacity of cover-load. Thus, ice-accumulation waves significantly alter the ice transport capacity of the cover-load. Before reaching the equilibrium condition, the ice transport capacity under ice jam is continually changing. As shown in Figure 9, the ice transport capacity at one cross section at any instant is defined as ice transport discharge $\left(Q_{T}\right)$ under the iceaccumulation wave under the condition of specific incoming ice discharge, flow condition and specific grain size of ice particle. Obviously, the ice transport capacity under ice-accumulation wave is an unsteady variable before ice jam reaches equilibrium condition. After ice jam achieves equilibrium condition, the ice

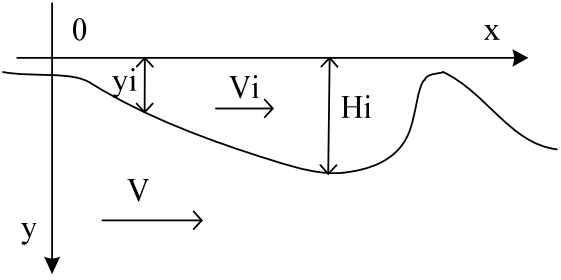

Fig. 9. Ice-accumulation wave and variable used.

transport capacity associated with the ice-accumulation wave must clearly equal the rate of incoming ice discharge from the upstream.

During the accumulation process of ice jam, the mass conservation equation can be written as follows:

$$
\frac{\partial Q_{T}}{\partial x}+(1-p) B \frac{\partial y_{i}}{\partial t}=0
$$

where $Q_{T}$ is the ice transport capacity; $t$ is time, $p$ is the porosity of accumulated ice jam and $p=0.4$ in this study, $y_{i}$ is the ice jam thickness at any cross section. When the movement speed of ice-accumulation wave is $V_{i}$, the equation for the movement of ice-accumulation wave can be written

$$
\frac{\partial y_{i}}{\partial t}+V_{i} \frac{\partial y_{i}}{\partial x}=0
$$

Combining Equations (14) and (15), we obtain

$$
\frac{\partial Q_{T}}{\partial x}-(1-p) B V_{i} \frac{\partial y_{i}}{\partial x}=0
$$

At any location $x_{0}$ at instant $t_{0}$,

$$
Q_{T}\left(y, t_{0}\right)-Q_{T}\left(h_{0}, t_{0}\right)=\int_{h_{0}}^{y}(1-p) B V_{i} d y=(1-p) B V_{i}\left(y-h_{0}\right)
$$

where $h_{0}$ is the thickness of ice jam at the cross section of wave trough of ice-accumulation wave.

At the cross section of wave trough of ice-accumulation wave, the ice transport capacity could be ignored. Then, the transport capacity of cover-load under ice cover can be determined by following equation:

$$
Q_{T}=\alpha(1-p) B H_{i} V_{i}
$$

where $\alpha$ is the correction coefficient for bottom form of iceaccumulation wave. It ranges from 0.6 to $0.8 ; H_{i}$ is the wave height at wave crest of ice-accumulation wave. Although almost all ice particles transported under ice jam are cover-load under ice jam, the effect of suspended ice particles in water should be also considered by adjusting the correction coefficient for bottom form of ice-accumulation wave $(\alpha)$. Therefore, for the waved accumulation of ice particles under ice cover, the transport capacity of cover-load can be determined as following,

$Q_{T}=0.255 \alpha(1-p) B V H\left\{1+C_{0}\left(\frac{V}{\sqrt{g H}}\right)^{2}-\left[\left(1+C_{0}\left(\frac{V}{\sqrt{g H}}\right)^{2}\right)^{2}-\left(8+4 C_{0}\right)\left(\frac{V}{\sqrt{g H}}\right)^{2}\right]^{0.5}\right\}\left(\frac{V}{\sqrt{g H}}\right)^{1.745}\left(\frac{H}{B}\right)^{-0.301}\left(\frac{Q_{i}}{Q}\right)^{0.026}$ 


$$
\frac{Q_{T}}{Q}=0.255 \alpha(1-p)\left\{1+C_{0}\left(\frac{V}{\sqrt{g H}}\right)^{2}-\left[\left(1+C_{0}\left(\frac{V}{\sqrt{g H}}\right)^{2}\right)^{2}-\left(8+4 C_{0}\right)\left(\frac{V}{\sqrt{g H}}\right)^{2}\right]^{0.5}\right\}\left(\frac{V}{\sqrt{g H}}\right)^{1.745}\left(\frac{H}{B}\right)^{-0.301}\left(\frac{Q_{i}}{Q}\right)^{0.026}
$$

Both Equation (20) and the formula for determining the surface ice discharge proposed by Beltaos (1995) have been derived based on mass conservation theorem, but can be used to determine the ice transport capacity under different conditions. The relation proposed by Beltaos (1995) can be used for calculating the surface ice discharge during river ice flowing period before river freeze-up. Equation (20) can be used to determine the ice transport capacity under waved ice accumulation. UrrozAquirre (1988) used models of ice floes to experimentally study ice transport capacity in a trapezoidal flume. Since it is difficult to determine both the shear force and roughness coefficient of the bottom of ice accumulation, calculation results using formulas for determining light bedload proposed by both Bagnold (1956) and Luque and Beek (1976) deviated far away from measured results, and cannot be used for determining ice transport capacity under waved accumulation. The formula for determining ice transport capacity in present study has been derived based on the mass conservation equation and the equations for the movement of ice-accumulation wave. Using measured data from experiments, the proposed formula has been validated.

As shown in Figure 8, based on measured ice transport capacities, the calculated ice transport capacities $\left(Q_{T} / Q\right)$ using the proposed Equation (20) agree closely with those of measured ice transport capacities $\left(Q_{T} / Q\right)$, especially if the ice transport capacities are relatively low.

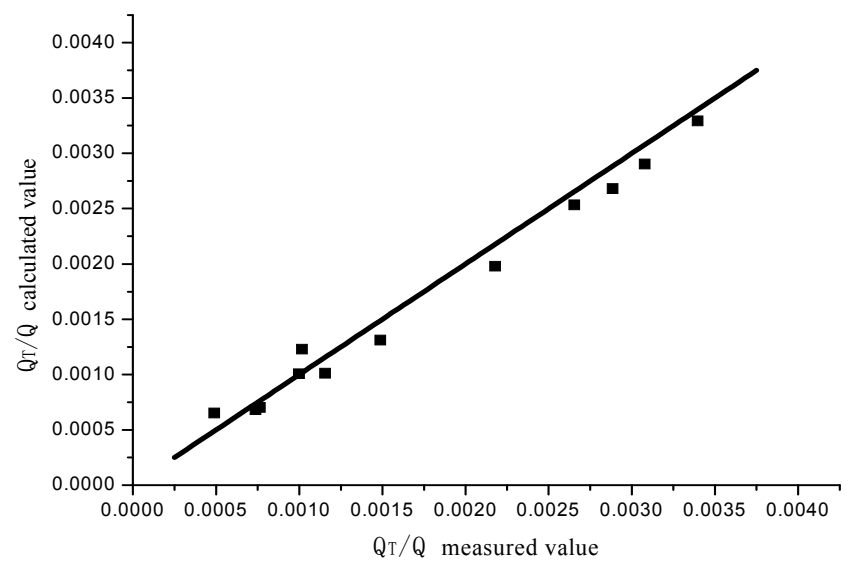

Fig. 8. Comparison of the calculated $Q_{T} / Q$ to those of measured results.

However, it must be pointed out that only one uniform model ice having the grain size diameter of $0.35 \mathrm{~cm}$ was available and used in this relation. The impact of grain size of ice particles on ice transport capacity under waved accumulation of ice is yet to be explored.

\section{CONCLUSIONS}

Laboratory experiments under different flow and incoming ice conditions have been carried out to study the mechanics, movement and characteristics of development of iceaccumulation wave and ice transport capacity. A criterion for the formation of ice-accumulation wave has been proposed and the dependence of wave height ice on flow Froude number $(\mathrm{Fr})$ has been assessed. Results indicate that higher flow Froude numbers result in larger ice waves. The propagation speed of the ice-accumulation wave is investigated based on mass conservation. A relation for estimating the celerity of an iceaccumulation wave has been derived. The transport capacity of frazil ice under waved accumulation of ice has also been studied based on mass conservation equation and the transport based on waved ice accumulation. It is found that, under the condition of the same flow depth, the moving speed of iceaccumulation wave clearly increases with flow Froude number. Also, the propagation speed of ice-accumulation wave decreases with the increase in the water depth, whereas an increase in water depth results in the decrease in the transport capacity. Finally, an estimate of ice transport capacity has been established. Calculated ice transport capacities using derived equation agree well with measured results for the case of known and uniform ice particle sizes.

Acknowledgement. This study is supported by the National Natural Science Foundation of China (Funding Number: 51379054). The authors are grateful for the financial support.

\section{REFERENCES}

Ackerman, N.L., Shen, H.T., 1983. Mechanics of ice jam formation in rivers. CRREL Report 83-31. U. S. Army Cold Regions Research and Engineering Laboratory, Hanover, New Hampshire, U.S.A.

Bagnold, R.A., 1956. The flow of cohesionless grains in fluids. Phil Trans of Royal Society of London, 249, A, 235-297.

Beltaos, S., 1993. Numerical computation of river ice jams. Canadian Journal of Civil Engineering, 20, 1, 88-89.

Beltaos, S., 1995. River Ice Jam. Water-Resources Publications, LLC, Water Resources Publications LLC, Highlands Ranch, Colorado, U.S.A., pp. 155-172.

Beltaos, S., 2012. Distributed function analysis of ice jam flood frequency. Cold Regions Science and Technology, 71, 2, 110.

Beltaos, S., Burrell, B.C., 2010. Ice-jam model testing: Matapedia River case studies, 1994 and 1995. Cold Regions Science and Technology, 60, 1, 29-39.

Calkins, D.J., Ashton, G.D., 1976. Arching of model ice floes: effect of mixture variation on two block sizes. CRREL Report 76-42, U S Army Cold Regions Research and Engineering Laboratory, Hanover, New Hampshire, U.S.A.

Ettema, R., Huang, H.P., 1988. Ice-rubble accumulation beneath barges in ice-covered waters. IAHR Journal of Hydraulic Research, 26, 4, 379-412.

Gao, P., Jin, G., Lu, B., 2003. Preliminary study on ice regime in the Middle Route of South to North Water Transfer Project". China Journal of Hydraulic Engineering, 11, 96-101.

Luque, R.F., Beek, R.V., 1976. Erosion and transport of bedload sediment. Journal of Hydraulic Research, 14, 2, 127 144.

Morse, B., Hessami, M., Bourel, C., 2011. Characteristics of ice in the St. Lawrence River. Canadian Journal of Civil Engineering, 30, 4, 766-774.

Nuttall, J.B., 1973. River modification and channel improve- 
ments. In: Proceedings of the Seminar on Ice Jams in Canada. National Research Council of Canada, Ottawa.

Shen, H.T., 2010. Mathematical modeling of river ice processes. Cold Regions Science and Technology, 62, 1, 3-13.

Sui, J., Fang, D., Zhou, Y., 1994. The variations of water level of ice jams. China Journal of Hydrology, 2, 18-24.

Sui, J., Karney, B., Fang, D., 2005. Variation in water level under ice-jammed condition - Field investigation and experimental study. Nordic Hydrology, 36, 1, 65-84.

Sui, J., Karney, B., Sun, Z., Wang, D., 2002. Field investigation of frazil jam evolution - a case study. Journal of Hydraulic Engineering, 128, 781-787.

Sui, J., Wang, J., Balachandar, R., Sun, Z., Wang, D., 2008. Accumulation of frazil ice along a river bend. Canadian Journal of Civil Engineering, 35, 158-169.

Urroz, G., 1988. Studies of ice jams in river bends. PhD Thesis. The University of Iowa, Iowa, U.S.A.

Urroz, G., Ettema, R., 1994. Small-scale experiments on ice jam initiation in a curved channel. Canadian Journal of Civil Engineering, 21, 5, 719-727.
Wang, J., 2002. A study on ice jam in balance transporting discharge. Journal of Hydroelectric Engineering, 1, 61-67.

Wang, J., Chen, P., Sui, J., 2011. Numerical simulations of ice jams in natural channels. China Journal of Hydraulic Engineering, 42, 9, 1117-1121.

Wang, J., Fu, H., Yin, M., Gao, Y., 2007a. Analysis of stages under ice-covered in winter. Advances in Water Science, 18, 1, 102-107.

Wang, J., Gao, Y., Yin, Y., Guo, L., Zhao, H., 2007b. An experimental study of ice jam formation and its thickness distribution in a curved channel. Journal of Glaciology and Geocryology, 29, 5, 764-769.

Wang, J., He, L., Chen, P., Sui, J., 2013. Numerical simulation of mechanical breakup of river ice-cover. Journal of Hydrodynamics, 25, 3, 415-421.

Wang, D., Shen, H.T., Sun, Z., 1993. Transport of frazil granules in Hequ reach of the Yellow River. Journal of Sediment Research, 4, 1-10.

Zufelt, J.E., Ettema, R., 2000. Fully coupled model of ice-jam dynamics. Journal of Cold Regions Engineering, 14, 1, 24-41.

Received 26 May 2017 Accepted 30 January 2018 